\title{
A revisão de texto por pares como metodologia ativa para o aprimoramento da escrita acadêmica
}

\author{
Peer Text Revision as an Active Methodology for Improving \\ Academic Writing
}

\section{Sueli Cristina Marquesi ${ }^{*}$}

suelimarquesi.sm@gmail.com

https://orcid.org/0000-0002-8792-0699

\author{
Andréa Pisan Soares Aguiar ${ }^{* *}$ (iC) \\ andreapisan@uol.com.br \\ https://orcid.org/0000-0002-2219-9546
}

\begin{abstract}
Resumo
Neste artigo, temos como objetivo apresentar a aplicação da metodologia de aprendizagem por pares adaptada a uma atividade de revisão de texto acadêmico, especificamente de resumo de dissertação de mestrado. Para o desenvolvimento dessa proposta, buscamos o aporte teórico que trata de metodologias ativas, bem como de interação e de escrita como processo recursivo, do qual faz parte a etapa de revisão. Entendemos que abordar o ensino da escrita acadêmica da perspectiva de tais metodologias permite alinhá-lo ao paradigma atual, segundo o qual, o aluno assume um papel ativo na própria aprendizagem, e o professor torna-se um orientador de caminhos que possibilitam a construção individual e coletiva de conhecimentos.
\end{abstract}

Palavras-chave: Escrita; Revisão; Interação; Metodologias ativas de aprendizagem; Aprendizagem por pares.

\section{Abstract}

In this article, we aim at presenting the application of the peer instruction methodology adapted to an academic text revision activity, particularly the review of a master's thesis abstract. For the development of this proposal, we sought the theoretical contribution that deals with active methodologies, as well as interaction, and writing as a recursive process, which is part of the revision stage. It is understood that approaching the teaching of academic writing from the perspective of such methodologies allows to align it with the

* Professora titular da Pontifícia Universidade Católica de São Paulo - PUC-SP, São Paulo, SP, Brasil.

** Pós-doutoranda na Pontifícia Universidade Católica de São Paulo - PUC-SP, São Paulo, SP, Brasil; bolsista PNPD/Capes.

\section{LINHA DÁGUA}


current paradigm, according to which the student has an active role in his own learning, and the teacher becomes an advisor of paths who enables the construction of the individual and collective knowledge.

Keywords: Writing; Revision; Interaction; Active Learning Methodologies; Peer Instruction.

\section{Considerações iniciais}

Este artigo, que se insere no campo dos estudos sobre escrita e revisão de textos acadêmicos, tem como objetivo aplicar, de forma adaptada, a título de exemplificação, a metodologia de aprendizagem por pares em uma atividade de revisão do texto acadêmico, especificamente o resumo de dissertação de mestrado, com vistas ao aprimoramento da produção textual. Tal perspectiva se mostra relevante quando falamos da escrita acadêmica, muitas vezes considerada complexa por parte de pós-graduandos, que precisam ser bemsucedidos do ponto de vista comunicacional no âmbito da pós-graduação. Sabemos que textos como artigos, dissertações e teses devem obedecer a uma estrutura determinada que, se não observada, pode gerar prejuízos ao produtor. Assim, conhecer a estrutura composicional de determinado gênero, seu propósito comunicativo, bem como a comunidade discursiva ao qual o gênero é dirigido, contribui para o sucesso comunicativo do produtor textual.

Também é importante considerarmos, no contexto atual em que estamos inseridos, as metodologias ativas de aprendizagem, pois vivemos um paradigma educacional em que o aluno deixa de ter o papel de sujeito receptor de conteúdos transmitidos pelo professor e passa a ter um papel ativo no processo de ensino e de aprendizagem, o que significa que ele aprende de forma mais autônoma, prática, colaborativa e interativa, tanto com o professor como com os colegas (BACICH; MORAN, 2017).

A fim de abordarmos esses aspectos e alcançarmos o objetivo proposto, pautamo-nos nos princípios teóricos que tratam: de escrita como processo (FIAD; MAYRINK-SABINSON, 1991; PINTO, 2010; 2014; 2016; 2017; FALLAHI, 2012; BAZERMAN, 2015; BELOTI; MENEGASSI, 2017; AGUIAR; MARQUESI, 2019), de revisão (PINTO, 2018; AGUIAR; MARQUESI, 2019), de interação (KOCH, 2006; 2007; CHARAUDEAU; MAINGUENEAU, 2008; VYGOTSKY, 2008; BAKHTIN [VOLOSHÍNOV], 2009 [1929]; SOBRAL, 2009), bem como de metodologias ativas de aprendizagem (BERGMANN; SAMS, 2016; MATTAR, 2017; MORAN, 2018; CHAQUIME; MILL, 2018) e, nesse último campo, mais especificamente, da aprendizagem por pares (ARAUJO; MAZUR, 2013; MATTAR, 2017; BACICH; MORAN, 2017; MORAN, 2018; FILATRO; CAVALCANTI, 2018).

Exemplificamos a atividade de revisão por pares por meio de um resumo acadêmico de dissertação em sua versão original e em sua versão revisada, esta resultante da aplicação da metodologia ativa anteriormente citada. A fim de explicitarmos o trabalho desenvolvido, organizamos este artigo em cinco seções: na primeira, apresentamos um breve panorama das 
metodologias ativas; na segunda, trazemos algumas dessas metodologias mais detalhadamente, em especial nosso recorte - a aprendizagem por pares; na terceira, abordamos a noção de interação; na quarta, discorremos sobre escrita e revisão; por fim, na última seção, exemplificamos a aplicação da revisão por pares.

\section{Breve panorama das metodologias ativas de aprendizagem}

Nos últimos anos, temos notado que a educação tradicional tem sido constantemente questionada, não só na escola, mas também fora dela, quanto aos métodos e às metodologias em que se baseia, em face das limitações que surgem no enfrentamento dos desafios sociais, tecnológicos e informacionais surgidos na atualidade.

Consideramos, diante dessa realidade, que a escola que conhecemos não tem respondido às demandas, especialmente dos alunos, que, como pontua Freire (2019), em muitos aspectos são ainda considerados como recipientes de conteúdos à espera de serem preenchidos passivamente pelo docente por meio de atividades mecânicas de transmissão, reprodução, memorização e arquivamento de informações. Os alunos passam, assim, pela educação formal sem que sejam devidamente instigados a refletir sobre tais conteúdos ou sem que o senso crítico lhes seja estimulado.

O contexto tecnológico e informacional mais recente tem exercido um papel significativo no processo de repensarmos as práticas pedagógicas, qualquer que seja o nível de ensino. As formas de comunicação, cada vez mais mediadas por dispositivos digitais e móveis, reconfiguraram os modos de interação entre os indivíduos e, consequentemente, as relações estabelecidas nos mais diversos âmbitos da sociedade.

Hoje, raramente escrevemos uma carta; utilizamos o e-mail. Tão pouco redigimos bilhetes; fazemos uso massivo dos aplicativos de mensagens. E caso não seja possível encontrar alguém pessoalmente, podemos fazê-lo por meio dos inúmeros recursos de videochamadas disponíveis. Esses não mais tão novos modos de estabelecer comunicação acabam por nos colocar em mundos nos quais não conseguimos mais separar as vivências on-line daquelas offline (BARTON e LEE, 2015), o que, de fato, constitui uma transformação social incontornável.

Nessa direção, apoiados em Jenkins (2008), Valente, Almeida e Geraldini (2017) refletem sobre o conceito de convergência entre os espaços virtual e físico. Tal conceito é evidenciado pela utilização cada vez mais frequente das mídias, das Tecnologias Digitais da Informação e da Comunicação (TDIC) e da conexão sem fio à Internet, que nos permitem acessar aplicativos, informações e serviços a qualquer tempo e em qualquer lugar.

Esse cenário permeado por tecnologia, embora não tenha sido o fator originário das metodologias ativas, certamente possibilita considerá-las a partir de novas perspectivas, mesmo porque tais tecnologias são um campo fértil para que o aluno se torne sujeito da própria formação e da construção de seu conhecimento. Assim, as metodologias ativas são vistas como 
estratégias pedagógicas capazes de oferecer possibilidades de ensino e aprendizagem que podem abarcar a complexidade imposta pelo contexto digital. Contudo, é importante ressaltar que tais metodologias não têm lugar apenas em meio tecnológico.

Se considerarmos uma abordagem histórica, Sócrates (469-399 a.C.), por exemplo, ensinava seus discípulos por meio de um método denominado maiêutica. O filósofo, em vez de lhes oferecer respostas prontas, indicava-lhes caminhos para a construção dos conceitos que precisavam aprender. Ele lhes propunha questionamentos que tinham por propósito fazê-los refletir por si mesmos, de modo que dessem luz às suas próprias verdades. Esse processo, segundo Mattar (2017), remete-nos às metodologias ativas, estratégias pedagógicas que têm entre seus propósitos estimular a reflexão e a autonomia do aluno.

A maiêutica socrática, posteriormente, conforme observam Albuquerque e Sampaio (2019), passou a constituir uma prática utilizada na área da pedagogia como método de ensino que leva os alunos a elaborarem as próprias respostas a questionamentos colocados em sala de aula. Isto, por sua vez, favorece o pensamento crítico relacionado a um tópico estudado, solicitando, assim, uma postura ativa no processo de ensino e aprendizagem.

Além da condição ativa a que o estudante é estimulado a experimentar, as metodologias ativas promovem a participação e o engajamento, uma vez que propiciam o trabalho em grupo de forma colaborativa. Nessa direção, Chaquime e Mill (2018, p. 442) ressaltam que as:

[...] metodologias ativas combinam tempos individuais e coletivos em projetos pessoais e de grupo e, com isso, buscam desenvolver competências cognitivas, pessoais e sociais, exigindo do estudante características como proatividade e colaboração [...] em diferentes situações e contextos.

Essa definição vai ao encontro da ideia defendida por Moran (2018), para quem as metodologias ativas são estratégias de ensino cujo objetivo é fazer com que o aluno participe na construção do processo de sua aprendizagem, de forma flexível, inter-relacionada e híbrida, características que respondem às demandas do mundo conectado e digital em que está inserido.

Em sua reflexão, o estudioso destaca dois conceitos importantes para compreendermos o sentido do aprender ativamente: o conceito de aprendizagem ativa e o de aprendizagem híbrida. O primeiro está relacionado ao papel de protagonista que o aluno assume no processo de aprendizagem ao se envolver nele de forma direta, participativa e reflexiva, desenvolvendo atividades mediadas pelo professor, este que assume o papel de facilitador da aprendizagem. $\mathrm{O}$ segundo conceito diz respeito à noção de flexibilidade, que permeia a abordagem de conteúdos, a realização de tarefas, o estabelecimento de tempos e espaços, bem como a adoção de materiais, técnicas e tecnologias.

Essa abordagem proposta pelo autor leva em conta o caráter transitório, ubíquo e móvel que tem a realidade tecnológica digital, o que amplia significativamente as "possibilidades de combinações, arranjos, itinerários, atividades" (MORAN, 2018, p. 2), das quais o professor pode se valer para tornar suas aulas mais motivadoras e levar os alunos a avançarem mais profundamente na aprendizagem. 
O objetivo da adoção de metodologias ativas é alcançar a aprendizagem ativa, caracterizada por uma abordagem disruptiva do modelo tradicional de sala de aula, um padrão em que o professor deteria o saber e o aluno possuiria um papel receptivo e passivo em relação ao conhecimento. Para essa abordagem disruptiva, a construção do conhecimento se dá de forma mais ativa, autônoma, colaborativa e participativa quando é considerado o contexto social do aluno no processo de aprendizagem, tornando-o mais significativo.

Ainda que as metodologias ativas não sejam novidade ${ }^{1}$, a educação formal, se desejar manter sua relevância, como observam Bacich e Moran (2018), precisa rever suas formas de ensinar. Isso inclui considerar novos modos de organizar currículos, pensar metodologias adequadas às necessidades dos alunos e aos objetivos de aprendizagem, bem como ajustar tempos e espaços de ensino e aprendizagem em função de estabelecer situações contextualizadas e significativas, conforme o ritmo do estudante.

\section{Algumas metodologias para a aprendizagem ativa}

As metodologias que têm como objetivo promover a aprendizagem ativa são inúmeras e ganharam evidência no contexto das TDIC, embora várias delas, como mapas mentais e aprendizagem baseada em equipes, ressignificadas hoje pelas novas tecnologias, sejam provenientes de épocas anteriores a elas.

A fim de buscarmos um entendimento mais amplo acerca do que vêm a ser metodologias ativas e aprendizagem ativa, e mesmo de evidenciarmos o papel que os alunos assumem como protagonistas do próprio aprendizado, apresentamos brevemente algumas dessas metodologias: a aprendizagem baseada em problemas, a sala de aula invertida, a aprendizagem baseada em projetos e a instrução por pares, esta, em que situamos o recorte deste trabalho e que adaptamos para a realização da etapa de revisão de resumo acadêmico.

\section{- Aprendizagem baseada em problemas}

A aprendizagem baseada em problemas (ABP), também conhecida como PBL, do inglês Problem-Based Learning, surgiu no final da década de 1960, na Faculdade de Medicina da Universidade de McMaster, Canadá. Na ocasião, os alunos de anos iniciais eram levados a aprender em pequenos grupos, com professores-tutores, tendo como objeto de estudo problemas, que eram casos reais de pacientes. O estudo desses problemas, com vistas a se buscar uma solução, permitiu que os alunos daquela universidade estabelecessem uma relação consistente entre a teoria e a prática.

1 Em busca no Google Scholar pela expressão "metodologias ativas", presente em títulos de artigos, constatamos o expressivo crescimento de pesquisas envolvendo esse objeto: entre 1990 e 1999, não identificamos a publicação de nenhum trabalho; entre 2000 e 2009, oito trabalhos; já entre 2010 e 2019, aproximadamente 1.090. Disponível em: https://scholar.google.com.br/. Acesso em: 10 out. 2020.

\section{LINHA DÁGUA}


Essa metodologia propõe que o estudante construa seu conhecimento com base em um problema, que constitui o ponto de partida para o aprendizado, este estruturado em ciclos de atividades da seguinte forma: primeiro, é apresentado o cenário do problema aos estudantes; depois, eles analisam e reformulam o problema, identificando fatos do cenário que são relevantes, o que ajuda a elaborar a representação do problema e o levantamento de hipóteses para se pensar em possíveis soluções; em seguida, busca-se identificar deficiências de conhecimento do grupo que dificultam ou impedem a solução do problema, etapa que resulta em estudos autodirigidos; posteriormente, cada aluno aplica os novos conhecimentos adquiridos do momento individual de aprendizado na solução coletiva do problema; ao final de cada ciclo ou da resolução de um problema, os alunos devem refletir acerca dos conhecimentos obtidos ao longo do processo (LOPES et al., 2011).

É importante diferenciar a ABP da simples resolução de problema. De acordo com Mattar (2017), na ABP, o objetivo não é simplesmente resolver um problema apresentado; em vez disso, o problema é a base para que os alunos identifiquem as próprias necessidades de aprendizagem, conforme tentam compreendê-lo. Nesse processo, eles reúnem, sintetizam e aplicam as informações obtidas, passando a trabalhar de forma efetiva para aprender com os integrantes do grupo e com o tutor, assim, lhes é possível chegar a uma solução.

\section{- Sala de aula invertida}

No bojo da metodologia ativa denominada sala de aula invertida, ou flipped classroom, está a otimização do tempo utilizado em sala de aula, uma vez que o estudo de determinado conteúdo ocorre a distância, antes da interação no momento da aula presencial. Dessa forma, "o que tradicionalmente é feito em sala de aula, agora é executado em casa, e o que tradicionalmente é feito como trabalho de casa, agora é realizado em sala de aula" (BERGMANN; SAMS, 2016, p. 11), portanto, a sala de aula passa a ser o local em que conteúdos estudados previamente são discutidos em grupo e em que há maior ênfase em atividades práticas, por exemplo, resolução de problemas, desenvolvimento de projetos e laboratório.

Essa estratégia, como bem pontuam Marquesi e Silveira (2015), pode ocorrer sem que sejam utilizados recursos tecnológicos tanto no momento da aula quanto fora dele, no entanto, determinados recursos, se utilizados de forma apropriada, podem facilitar e otimizar significativamente as situações de aprendizagem. De qualquer modo, as aulas tradicionais, que costumam ser expositivas e centradas no docente, passam a ser espaços de discussão sobre dúvidas e atividades pertinentes a temáticas estudadas anteriormente.

Bergmann e Sams (2016) observam que a sala de aula invertida coloca o aluno no centro da aprendizagem, pois ele tem o compromisso de assistir a vídeos como atividade prévia à aula e, na sala de aula, fazer perguntas relacionadas ao conteúdo visto a priori; ao professor cabe promover feedbacks qualificados. O aluno deve solicitar ajuda do professor sempre que precisar de esclarecimentos necessários para a compreensão de conceitos. Desse modo, o papel do

\section{LINHA DÁGUA}


professor na sala de aula não é de transmissor de informações, mas de mediador do conhecimento, que ampara o estudante no processo de construção do conhecimento e de consolidação da aprendizagem.

Para que essa dinâmica se efetive, o desenvolvimento de atividades nessa metodologia requer a inversão do planejamento das aulas e ajustes no currículo, de maneira a diminuir as aulas expositivas e proporcionar interações mais produtivas entre alunos e entre estes e o docente, interações que sejam capazes de "engajar os alunos no conteúdo, aperfeiçoar o tempo, valorizar o conhecimento do professor e pré-requisitos dos alunos" (SOUZA, 2020, s. p.).

Além da reorganização do processo de ensino, a sala de aula invertida demanda ações diversas tanto por parte dos professores quanto por parte dos alunos. Do lado do docente, cujas ações a serem desenvolvidas englobam produção de material ou curadoria de conteúdo, elaboração de avaliações, planejamento e condução de aulas, é preciso que ele esclareça ao estudante as atividades a serem desenvolvidas antes, durante e depois das aulas, os objetivos de cada etapa do estudo, os conteúdos que deve acessar, por exemplo, vídeos, textos e sites, orientações que, segundo Mattar (2017), podem ser elencadas em um guia, possivelmente disponibilizado no ambiente virtual de aprendizagem. Do lado do aluno, cujas ações devem ir na direção de assumir o papel principal na discussão dos conteúdos e de interagir colaborativamente com os colegas e com o professor, é preciso que ele assista a vídeos e realize atividades propostas. Nesse sentido, Bergmann e Sams (2016) indicam que seja realizado um treinamento, no começo do ano, por exemplo, para que o aluno saiba como assistir aos vídeos de forma eficaz, fazer anotações e registrar dúvidas, as quais serão discutidas na sala de aula.

\section{- Aprendizagem baseada em projetos}

$\mathrm{Na}$ aprendizagem baseada em projetos, também conhecida como Project Based Learning, os alunos trabalham no sentido de resolver um problema observado na comunidade ou de desenvolver um projeto relacionado com a vida fora da escola. $\mathrm{O}$ desenvolvimento da atividade, segundo esclarecem Filatro e Cavalcanti (2018), pode ocorrer em um período mais longo: inicia quando o docente apresenta um tema instigante e envolvente, orientador das ações relacionadas ao projeto; na sequência, os alunos são informados sobre prazos, escopo do trabalho, expectativas em relação a resultados e critérios de avaliação.

Essa metodologia leva os alunos a lidarem com questões interdisciplinares, tomarem decisões e agirem tanto sozinhos como em equipe; além disso, são enfatizadas as habilidades de pensamento crítico e criativo, e a percepção de que há várias formas de se realizar uma mesma tarefa. Tais competências são consideradas necessárias no contexto do século XXI (BACICH; MORAN, 2017), e exigem uma atuação em espaços complexos, presenciais e virtuais, uma adoção de novos modos de relacionamento e de novos meios para trocar informações e construir conhecimento.

Os modelos da metodologia de aprendizagem baseada em projetos são variados. Bacich e Moran (2018) explicam que há projetos mais breves, de uma ou duas semanas, projetos

\section{LINHA D'́GUA}


ambientados na sala de aula, que tratam de um assunto específico, e projetos cujas soluções são complexas, envolvendo temas transversais e interdisciplinaridade, os quais podem se desenvolver por um período mais longo, como um semestre ou um ano. Em todo caso, a metodologia é sempre permeada pelo princípio da aprendizagem colaborativa e pelo trabalho coletivo que visa a um objetivo: buscar soluções para um problema identificado.

\section{- Instrução por pares}

A metodologia denominada instrução por pares, do inglês peer instruction (PI), conhecida também como aprendizagem por pares ou instrução pelos colegas, que enfocamos neste artigo, foi criada na década de 1990, por Eric Mazur, docente de disciplinas de introdução à física na Universidade de Harvard. Araujo e Mazur (2013) explicam que as bases dessa metodologia são o estudo prévio de conteúdos disponibilizados pelo professor e a apresentação de aspectos conceituais, na sala de aula, para que os estudantes discutam entre si. O objetivo principal da instrução por pares, segundo os autores, é "promover a aprendizagem dos conceitos fundamentais dos conteúdos em estudo, através da interação entre os estudantes" (p. 367). Segundo Mattar (2017), essa metodologia, como concebida por Mazur, inicia antes da aula propriamente dita, assim, os alunos leem o material didático e as anotações disponibilizadas pelo professor, ações que buscam incentivar a pesquisa a fontes primárias e a aprendizagem nelas baseada.

De maneira a assegurar a leitura prévia do material, três questões abertas são propostas aos alunos, que as respondem pela web antes da aula presencial. Apoiado em Crouch e Mazur (2001, p. 973), Mattar (2017, p. 42) explica que as duas primeiras perguntas abordam aspectos complexos do material sugerido, e que a terceira é sempre a mesma: "O que achou difícil ou confuso na leitura? Se nada foi difícil ou confuso, conte-nos o que achou mais interessante. Por favor, seja o mais específico possível". Ao verificar as respostas dos estudantes a essas questões, o docente tem a possibilidade de preparar aulas mais eficientes, uma vez que é capaz de identificar elementos que precisa enfatizar, contemplando, assim, as reais necessidades dos alunos.

Já na sala de aula, é feita a explanação breve de um conceito, problematizando-o; na sequência, aplica-se um teste, que pode ser do tipo múltipla escolha. Esse teste deve ser respondido de forma rápida e individual pelos alunos; as respostas são transmitidas para o computador do professor ou diretamente on-line. De modo que todos possam ter conhecimento das respostas, elas são projetadas para a classe; o professor pode gerar relatórios, o que lhe permite visualizar o nível de compreensão individual, o aproveitamento e progresso da turma.

Espera-se que a porcentagem de acertos das respostas dos estudantes às questões conceituais fique entre $30 \%$ e $70 \%$ antes da etapa de discussões. Se menos de $30 \%$ dos estudantes acertarem as respostas, é possível que o teste esteja ambíguo ou que poucos alunos tenham compreendido os conceitos, então, o docente deverá promover novas explicações acerca do conteúdo, de forma mais detalhada e com mais vagar, a fim de se fazer compreender. Se

\section{LINHA D'́GUA}


mais de 70\% dos alunos acertarem, as discussões posteriores não terão muitos benefícios; nesse caso, o docente explica brevemente a resposta e passa para o tópico seguinte. Havendo um índice razoável de acertos, o docente orientará os alunos a formarem grupos para discutir os temas propostos. Como se pode notar, o resultado das respostas do teste inicial ditará o rumo das aulas.

Ao seguir para a etapa de discussão, o tópico é retomado, e os estudantes, conversando com os colegas nos grupos, tentam convencê-los de que sua resposta está correta, o que caracteriza o "ensino por pares" (MATTAR, 2017). O professor circula entre os grupos e pode participar de algumas discussões, que devem levar de dois a quatro minutos. Trata-se de um momento de muita interação entre os estudantes e, por vezes, entre estes e o professor. Novamente o professor solicita que os alunos respondam ao teste, a fim de verificar se compreenderam o conceito.

No caso de, nessa etapa, a maioria dos estudantes tiver acertado, o docente comenta a resposta correta e explica a solução do problema, passando a um novo tópico. O ciclo, de 13 a 15 minutos, se repete. Se, ao contrário, poucos alunos tiverem acertado, o professor retorna ao mesmo tópico, explicando-o devagar e de forma mais detalhada, para, então, realizar nova avaliação, com outro teste conceitual. O esquema da metodologia da aprendizagem por pares está representado na Figura 1, a seguir.

Figura 1. Diagrama das etapas da aprendizagem por pares

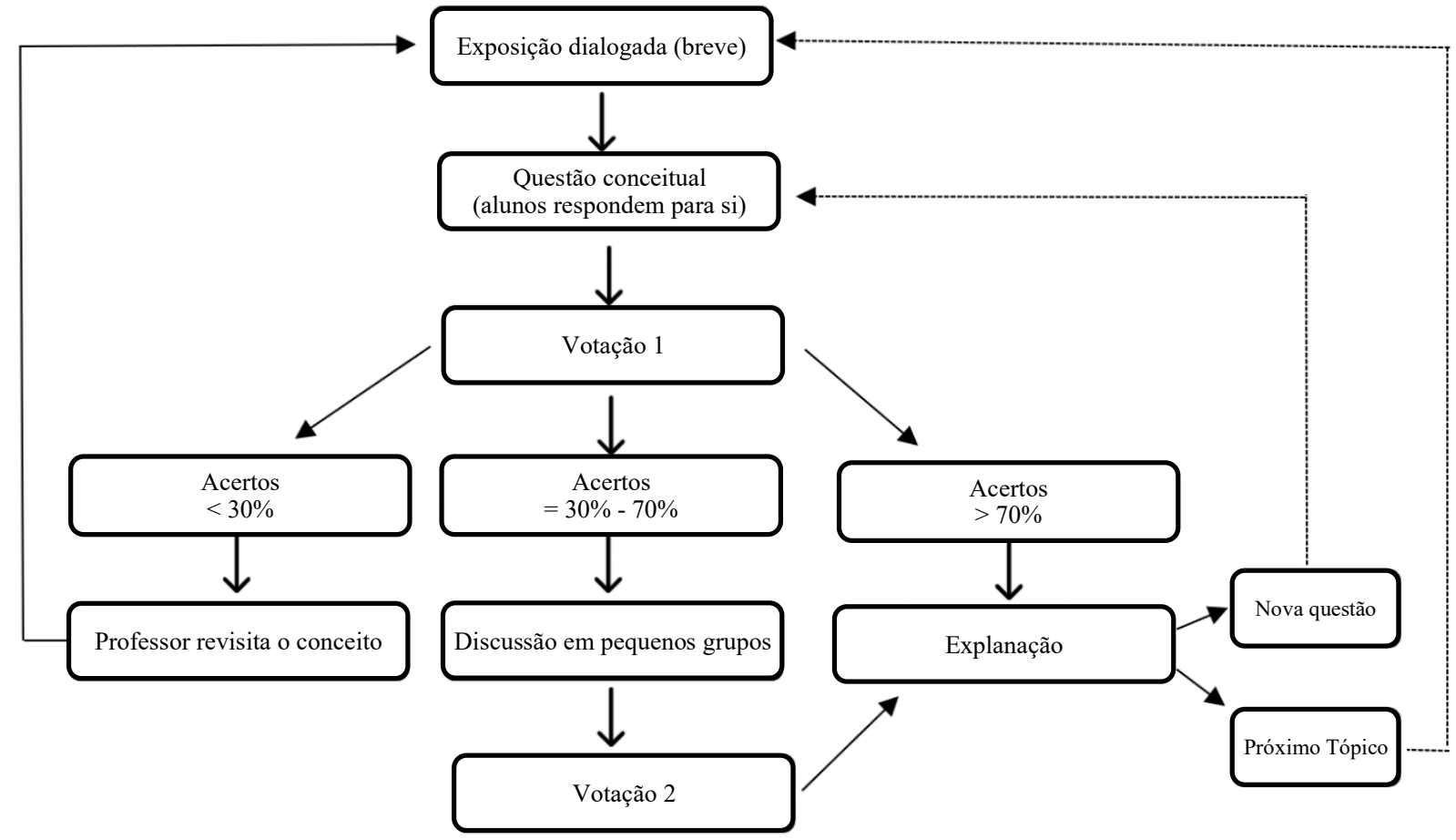

Fonte: Araujo e Mazur (2013, p. 370).

\section{LINHA DÁGUA}


Mattar (2017) ressalta que não só durante a aula, mas também após ela, a instrução por pares incentiva os alunos a solucionarem problemas, por isso, o docente não deve se limitar a apresentar conteúdos; ele deve ir além e disponibilizar aos alunos estratégias para a resolução dos problemas, assim, a lição de casa envolve a solucionar questões expostas em sala de aula, em que os estudantes trabalham de forma colaborativa e interativa.

Filatro e Cavalcanti (2018) ressaltam que, apesar de a instrução por pares ter como foco a aprendizagem mais conceitual e a elaboração de uma resposta correta, o que parece ser um contrassenso às metodologias ativas, mais abertas e flexíveis, essa metodologia é considerada ativa porque leva o aluno a assumir o papel de instrutor ou de professor de seus colegas, favorecendo a aprendizagem de uns com os outros.

No estudo que ora apresentamos, propomos a utilização de uma variação da aprendizagem por pares, resultante da adaptação dessa metodologia ao contexto da atividade de revisão textual, em que nos valemos de duas das etapas constantes na Figura 1: exposição dialogada (breve) e discussão em pequenos grupos, que denominamos, respectivamente, (1) abordagem dialogada breve do conteúdo teórico e (2) discussão em pequenos grupos. Na etapa 1, o referido conteúdo teórico, no âmbito deste trabalho, diz respeito a dois elementos: 1) gênero textual resumo acadêmico, uma vez que, em nossa proposta de atividade, recorremos a um resumo de dissertação de pós-graduando produzido antes da etapa de revisão, e 2) categorias de revisão denominadas conteúdo, estrutura, referências e citações, e gramática. Na etapa 2, alunos, orientando-se pelos conteúdos teóricos, discutem os ajustes a serem feitos no resumo e realizam sua revisão.

Às duas etapas mencionadas, adicionamos outras três, que entendemos serem necessárias no âmbito da aprendizagem da revisão do texto acadêmico: (3) apresentação $e$ discussão das versões revisadas pelos grupos, (4) reescrita dos textos pelos grupos e (5) apresentação das versões finais dos grupos na classe. O esquema da metodologia de aprendizagem por pares adaptada à revisão textual está ilustrado na Figura 2, e suas etapas são apresentadas em detalhes na seção 5, em que exemplificamos a revisão por pares. 
Figura 2. Diagrama das etapas da revisão por pares

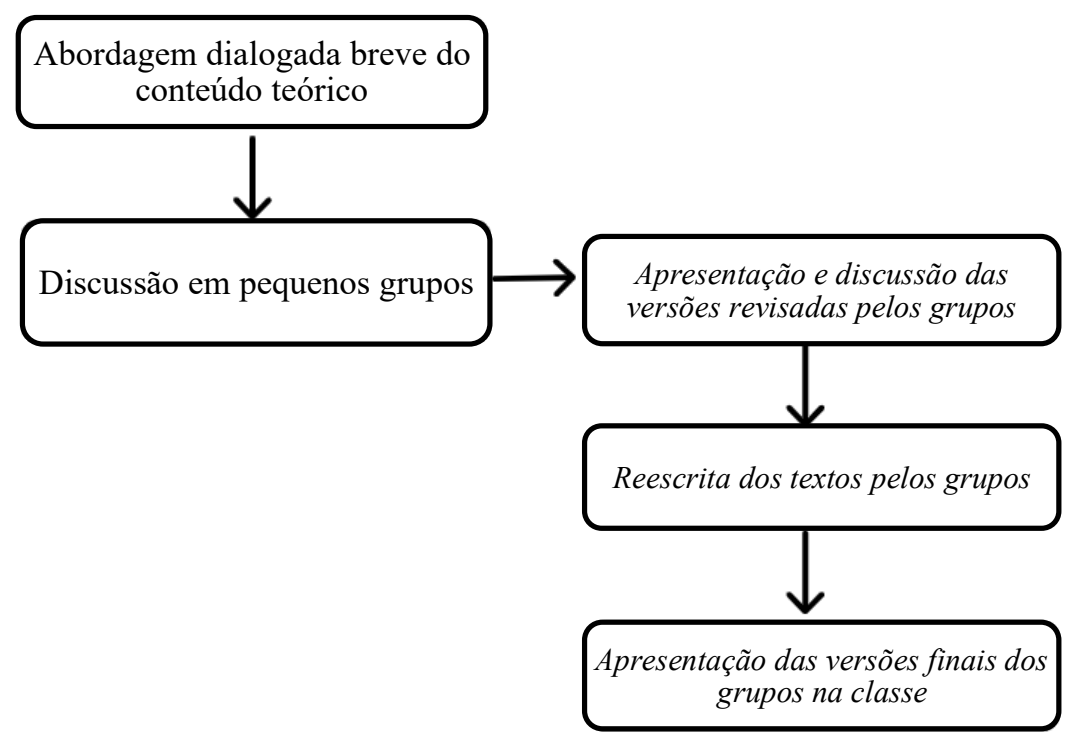

Fonte: elaborado pelas autoras.

A nosso ver, a revisão de texto por pares pode constituir uma metodologia para o aprimoramento da escrita do texto acadêmico na pós-graduação. Por meio dela, os alunos são levados a trocar conhecimentos, compartilhar perspectivas acerca da composição textual e desenvolver competências para a escrita como processo, do qual faz parte a etapa de revisão.

\section{A interação como base para as metodologias ativas}

Entendemos que o desenvolvimento de atividades baseadas na perspectiva colaborativa, em que se dá a troca e a construção compartilhada de conhecimento, como é o caso da aprendizagem por pares e, especificamente, da revisão de textos por pares, requer pensarmos no conceito de interação. Essa reflexão é fundamental, uma vez que, nessa metodologia, temos uma atividade em que estão envolvidos dois sujeitos que compartilham um mesmo espaço e tempo, bem como saberes e habilidades que são mobilizados para atingir um objetivo: o aprimoramento do texto por meio da revisão.

Refletir sobre interação requer considerar os pressupostos defendidos por Bakhtin (Voloshínov) (2009 [1929]), para quem a linguagem é permeada pela interação e pelo dialogismo, bases da criação dos discursos e da própria linguagem. Nessa concepção, não cabe a ideia de que a linguagem seja monológica e de que a língua seja um sistema formal imutável, descolado dos contextos de uso; ao contrário, ambas, linguagem e língua, devem ser entendidas como atividades fluidas, situadas e dinâmicas, que envolvem práticas socioculturais.

De acordo com o autor, é na interação que a linguagem é produzida, na feição de uma prática social mediadora da relação entre os sujeitos. Nesse sentido, a comunicação constitui um evento interativo e contínuo, uma vez que os enunciados produzidos pelo sujeito estão 
entrelaçados com enunciados anteriores; a existência do diálogo pressupõe um sujeito que enuncia; não há como o sujeito agir sem que participe de uma interação, ainda que o outro não esteja presente fisicamente; e não existe interação sem diálogo, que envolve mais de um sujeito, ainda que este seja imaginário ou o próprio sujeito (SOBRAL, 2009).

Em sua exposição sobre o conceito de interação criado pelo Círculo de Bakhtin, Sobral (2009) menciona os quatro níveis da interação:

- nível do intercâmbio verbal - base dos demais níveis, pelos quais este primeiro é afetado, pois "a interação 'fundadora' é justamente o contato verbal, direto ou indireto, entre ao menos dois sujeitos" (p. 42);

- nível do contexto imediato do intercâmbio social - é mais amplo e abstrato, e nele estão presentes os lugares ou papéis sociais, a posição e a imagem dos interlocutores e as formas de interação social passíveis de ocorrer entre os sujeitos;

- nível do contexto social mediato - envolve um domínio mais amplo de atividades - os lugares de interação e suas exigências aos participantes da interação -, e diz respeito ao plano de organização socio-histórica de cada sociedade;

- nível do horizonte social e histórico - engloba a cultura de forma ampla, as relações entre culturas, os períodos da história, o espírito de época.

Dessa forma, como argumenta Sobral (2009), a interação é condicionada pela situação socio-histórica e pessoal dos participantes, assim como pelas condições materiais e institucionais em que se dá o intercâmbio verbal. Tais elementos condicionam o discurso por meio da interdiscursividade e da relação dialógica que se estabelece entre os sujeitos do discurso.

Essas noções que envolvem a interação estão presentes na explicação de Charaudeau e Maingueneau (2008) sobre o termo interação, o qual, esclarecem os autores, surgiu primeiro no campo das ciências da natureza e das ciências da vida, e, a partir da segunda metade do século XX, foi adotado no campo das ciências humanas para designar as interações comunicativas. Tomando a definição de Goffman (1973), ressaltam os dois principais usos que se fazem do termo: um se refere ao processo de influências recíprocas que os participantes do ato comunicativo exercem entre si; outro diz respeito ao lugar em que se desenvolve o jogo de ações e reações que ocorre em uma troca comunicativa.

Assim, podemos entender que a interação se estabelece entre indivíduos em uma troca comunicativa, um processo inerente à própria condição de ser social que cada sujeito traz consigo, como bem pontua Marcuschi (1998, s. p., apud FÁVERO et al. 2010, p. 91-92):

[...] tendo o ser humano que agir na relação com seus semelhantes de maneira ordenada, deve sempre interagir, ou seja, atuar na perspectiva de uma ação coordenada. Isto faz com que as ações humanas construam-se, no geral, como interações, na maioria das vezes mediadas pelo uso da língua que por sua vez facilita a relação intersubjetiva.

\section{LINHA D'́GUA}


O elemento linguístico, ou seja, língua e linguagem, é central no processo interativo, uma vez que possibilita o estabelecimento de relações entre os indivíduos. Vygotsky (2008), que também aborda o aspecto interacional presente nas relações humanas em sociedade, observa que o desenvolvimento do sujeito e a própria construção do conhecimento, esta uma atividade situada que envolve circunstâncias socio-históricas, culturais e materiais, se dão por meio da interação pela linguagem e pela ação.

A interação pela linguagem também é objeto de discussão de Koch (2007), para quem, entre as três concepções de linguagem - linguagem como representação, como instrumento e como forma ("lugar") - está aquela que a considera como atividade, uma forma de ação interindividual e finalisticamente orientada, e como lugar de interação, que permite aos sujeitos a prática de atos variados, os quais demandarão do outro determinadas reações e comportamentos, resultando em vínculos antes inexistentes. Assim, com base na relação interpessoal estabelecida, e também na relação com o mundo, o sujeito se desenvolve interpessoalmente, ou seja, ele se torna capaz de pensar sobre si e sobre a realidade em que está inserido, podendo agir sobre ela (VYGOTSKY, 2008).

Vale destacar que, para Vygotsky (2008), o sujeito se torna ativo e interativo em decorrência da interação social que ocorre em contextos socio-históricos e culturais diversos, processo que molda e transforma continuamente as relações sociais. Ao estabelecer contato com outros sujeitos e com o contexto, o indivíduo constrói e apropria-se de conhecimentos, o que lhe permite compreender e dar sentido ao mundo a sua volta.

A interação é, assim, um elemento central nas práticas de linguagem e envolve compartilhar conhecimentos e atenção, uma vez que "os eventos linguísticos não são a reunião de vários atos individuais. São, ao contrário, uma atividade que se faz com os outros, conjuntamente, "mas não só isso, na interação é que se constrói, em grande parte, o contexto, e este passa a constituir a própria interação" (KOCH, 2006, p. 31-32).

Em um estudo em que propõe um modelo de processamento estratégico do discurso, van Dijk (1992) elenca os pressupostos básicos, cognitivos e contextuais, dos modelos de processamento do discurso. Entre os pressupostos contextuais, o autor define o pressuposto pragmático e o pressuposto interacionista, os quais concorrem para o entendimento da atividade de revisão por pares que defendemos neste artigo.

$\mathrm{O}$ primeiro pressuposto, o pragmático, refere-se às intenções dos interlocutores que permeiam o discurso. Nessa direção, ao revisar um texto, o sujeito lida não só com objetos linguísticos ou cognitivos, mas também com os resultados provenientes de algum tipo de ação social; o segundo, o interacionista é uma generalização do anterior; diz respeito à interação entre as intenções do sujeito ao comunicar uma mensagem e as intenções do receptor de compreendê-la, ambos pertinentes ao ato social de compartilhar, o que é enfatizado por meio da atividade de revisão por pares que propomos. 


\section{Escrita como processo - o lugar da revisão}

A noção de escrita que adotamos neste estudo, como já defendemos em trabalho anterior (AGUIAR; MARQUESI, 2019), e como postulam Pinto (2010; 2014 e Fallahi (2012), é a de processo, que se contrapõe à ideia de que a escrita é um meio para se obter um produto final, como um artigo científico ou uma dissertação de mestrado, por exemplo. Fallahi (2012, s. p.) observa que a abordagem de escrita como processo requer que o professor desempenhe o papel de "coaching" de seus alunos, solicitando-lhes que façam revisões de seus textos a cada passo da produção textual. Já a outra abordagem, de escrita como meio para se obter um produto final, envolve um professor que geralmente atua como editor, que comenta aspectos como estrutura, conteúdo, clareza, objetividade do texto.

Considerar a escrita como processo implica considerá-la de uma perspectiva não linear, que se contrapõe ao paradigma tradicional, ou, nas palavras de Morin (2011), ao paradigma simplificador. Neste paradigma, fundado na visão de mundo newtoniana-cartesiana, o conhecimento é construído linearmente, com base no estudo isolado das partes de um fenômeno em observação, sem que seja levado em conta seu contexto. Assim, essa concepção reduz, fragmenta e separa o conhecimento, fazendo com que ocorra sua simplificação.

No âmbito da escrita, tal perspectiva conduz à percepção de que escrever é uma tarefa fácil e que se dá de modo automático, simplesmente colocando-se palavras sobre o papel em branco. Desse ponto de vista, a escrita não ocorre em etapas, pré-escrita, escrita, revisão, edição e reescrita, como postula Pinto $(2010 ; 2014)$, mas como uma ação única, a de escrever simplesmente.

Bazerman (2015), que também considera a escrita como processo, oferece-nos uma visão da complexidade presente no percurso de se chegar ao texto finalizado, que envolve "detalhes e níveis de trabalho que precisam ser enfrentados" (p.187), pois:

[...] escrever é, inevitavelmente, um processo, mesmo que sejam apenas dois minutos para ler um e-mail, reconhecer que precisamos responder, decidir o que precisamos comunicar, escolher as melhores palavras e revisar antes de pressionar o botão 'enviar'. Não importa que o processo dure dois minutos ou uma década: os impulsos e as palavras iniciais na página podem não estar nem perto do que o documento final será. (BAZERMAN, 2015, p. 188).

O autor destaca que tal processo não é constituído por etapas que se dão em uma sequência fixa, como comumente se ensina aos estudantes. Tal visão, por sua vez, reforça o paradigma da complexidade mencionado anteriormente, isso porque "cada tarefa, cada conjunto de condições e cada personalidade trabalhando com conjuntos específicos de recursos exige formas diferentes de trabalhar e diferentes sequências de eventos e atenção" (BAZERMAN, 2015, p. 188).

Retomando o trabalho de Fiad e Mayrink-Sabinson (1991), em que as autoras defendem a concepção de escrita como trabalho, baseada na perspectiva interacionista da linguagem,

\section{LINHA D'́GUA}


notamos também a abordagem de processo, incluída nele a etapa de revisão. Para as autoras, "a escrita é uma construção que se processa na interação e que a revisão é um momento que demonstra a vitalidade desse processo construtivo, [assim, pensam] a escrita como um trabalho de reescritas" (p. 55).

Dessa mesma perspectiva compartilham Beloti e Menegassi (2017), para quem o trabalho de escrita se desenvolve por meio das etapas: de planejamento, em que o produtor projeta a escrita de seu texto, considerando os elementos linguístico-discursivos necessários e as condições determinadas; de execução da escrita, em que o produtor dá andamento ao que foi planejado anteriormente e passa à produção textual propriamente dita; de revisão, em que o produtor faz a releitura do texto, observando a adequação ou não às condições de produção, e que pode ou não levar à reescrita; de reescrita em que o produtor, depois de identificar o que precisa ser revisado e reescrito, produz outro texto, com vistas a adequá-lo à situação de enunciação.

$\mathrm{O}$ ato de escrever se torna ainda mais complexo se considerarmos a leitura, que leva a rever o modo de pensar e de se expressar, dinâmica que também evidencia a escrita como processo. Nessa acepção, a escrita, em sua reformulação, envolve "re-elaborações de ideias que se servem da leitura como apoio à memória em exercício", a essência do ato de escrever, permeado pelo "diálogo entre a leitura e a escrita com a intervenção inevitável do pensamento" (PINTO, 2010, p. 111-112).

Fallahi (2012), apoiada no estudo de Simpson, Stahl e Francis (2004), destaca que muitos estudantes, baseados no pressuposto de que escrever é uma tarefa que não impõe dificuldades, mostram-se surpresos ao perceberem que várias revisões podem ser necessárias para se chegar a uma produção textual satisfatória. De fato, a escrita "é um ofício que também tem os seus ossos"; mesmo escritores experientes reveem suas produções e, em razão disso a revisão e a reescrita podem ser "o começo do processo da escrita e não o seu fim como pretende o modelo linear de estados” (PINTO, 2018, s. p.).

Tendo em vista a noção de que a escrita não ocorre em um processo linear de ações, Pinto (2018) ensina que, na etapa de revisão, o rascunho constitui um ponto de partida para uma nova versão do texto, que está em aprimoramento. Nesse sentido, ressalta a autora, que a força da revisão impulsiona a reescrita, em um "movimento incessante de reformulações, de adições, de cortes e de ajustamentos, que consolida uma escrita que vive, finalmente, do ofício de escrever/compor" (s. p.).

Diante do exposto, defendemos a importância de se considerar, no contexto de ensino da escrita, particularmente do texto acadêmico, a etapa de revisão como essencial para promover o aprimoramento da escrita do aluno, o que propomos por meio da aplicação da metodologia peer instruction adaptada à revisão textual. 


\section{Peer instruction adaptada: a revisão por pares}

Na sequência, sugerimos a aplicação da revisão por pares, adaptada da peer instruction, aprendizagem por pares, que explicamos anteriormente. Para tanto, selecionamos dois textos do gênero resumo acadêmico de dissertação de mestrado, um texto original e sua versão revisada $^{2}$. São contempladas as cinco etapas, conforme constam na Figura 2.

\section{- Etapa 1 - Abordagem dialogada breve do conteúdo teórico}

Nesse momento, o professor aborda, de forma dialogada, em poucos minutos, os aspectos teóricos relacionados ao gênero textual resumo acadêmico, cujo propósito comunicativo é apresentar informações do texto mais longo de forma suscinta, de modo que o leitor possa ter uma ideia do conteúdo que virá posteriormente (MOTTA-ROTH; HENDGES, 2010). Elementos característicos da estrutura composicional desse gênero, como tema, justificativa, problema, objetivos, aporte teórico e metodológico e resultado alcançado (MOTTA-ROTH; HENDGES, 2010; LEITE, 2006) também devem ser explicitados aos estudantes.

Além disso, quatro categorias são elencadas, as quais servirão de base para a revisão do texto: 1) conteúdo, diz respeito à progressão textual, que envolve informações dadas e novas que aparecem no texto e o fazem progredir; 2) estrutura, relacionada à relação estabelecida entre os elementos linguísticos que compõem o texto; 3) citações e referências, pertinente às normas estabelecidas pela Associação Brasileira de Normas Técnicas - ABNT - (no caso deste estudo) para elaboração de trabalhos acadêmicos; 4) gramática, referente a aspectos da norma culta, que deve ser observada em contextos formais de comunicação, como é o acadêmico, em que são produzidos resumos semelhantes aos apresentados na presente proposta.

\section{- Etapa 2 - Discussão em pequenos grupos}

O docente divide a classe em grupos de quatro alunos e distribui o resumo de dissertação em sua versão original, exibida adiante, a fim de que os estudantes discutam entre si a revisão textual a ser feita, com base no que foi abordado na etapa 1, ou seja, as características do gênero resumo acadêmico e as quatro categorias orientadoras da revisão.

\section{- Etapa 3 - Apresentação e discussão das versões revisadas pelos grupos}

Cada grupo apresenta para a classe a versão revisada do respectivo resumo, explicando suas escolhas. Nesse momento, o professor esclarece dúvidas e pode mediar contribuições que busquem promover melhorias nas versões dos colegas.

2 Os textos compõem o corpus de pesquisa de pós-doutorado em desenvolvimento e foram adaptados para este artigo.

\section{LINHA DÁGUA}




\section{- Etapa 4 - Reescrita do texto pelos grupos}

Com base no trabalho desenvolvido na etapa 3, o professor solicita aos grupos a reescrita do texto, buscando solucionar possíveis problemas que, eventualmente, ainda permaneceram na versão apresentada à classe.

\section{- Etapa 5 Apresentação da versão final dos grupos na classe}

Cada grupo apresenta sua versão final do resumo após a reescrita, ocorrida na etapa 4.

A seguir, apresentamos o conjunto de textos, a versão original (texto 1) e a versão revisada (texto 2), esta última, a título de exemplo de uma produção final.

\section{Texto 1 - versão original ${ }^{3}$}

O trabalho situado na linha de pesquisa Leitura, Escrita e Ensino de Língua Portuguesa da Pontifícia Universidade Católica de São Paulo - PUC/SP tem o intuito de tratar das Redações Saresp, com o tema: Análise de Produções argumentativas dos alunos do $9^{\circ}$. ano do ensino fundamental no Saresp de 2014, tomando por base a escrita do texto argumentativo, e das construções que materializam o texto. Queremos saber a organização das sequências textuais argumentativas e os operadores argumentativos utilizados em textos de artigos de opinião. O intuito é discutir como se constrói a argumentação nos textos do Saresp e também identificar as sequências e os operadores nos textos e refletir sobre a relação entre essas sequências e operadores na argumentação nesses textos.

Importante para o ensino de língua portuguesa, que enfrenta desafios no que diz respeito à leitura, produção e interpretação de textos como resultado do processo de compreensão e transposição de ideias desenvolvidas, que busca compreender a produção escrita de textos, dentro da perspectiva sociocognitiva-interacionista, tomando por base os estudos de Marcuschi (2008). Baseamo-nos também em Travaglia (2017).

Fundamentamo-nos na perspectiva da estrutura da argumentatividade, que identificam o texto como um objeto concreto, material e empírico resultante de um ato de enunciação circundado e determinado pelo discurso, e que parte da enunciação e das práticas discursivas, para delimitar o campo da linguística textual e contribuir com os processos de interação comunicativa.

Tomando o protótipo da sequência argumentativa de Adam (1992, 2011), e dos encadeamentos argumentativos em Koch (2009) e Cabral (2017) tomamos as estratégias da argumentação discursiva que permite lançar mão de uma tese direcionada ao outro, com a função de convencer, persuadir ou construir uma representação. Esse formato tem o intuito de dividir cada etapa da construção das redações para uma melhor visualização, entendimento, facilitar a compreensão e localização de cada parte do texto constituído. Palavras Chave: argumentação; produção argumentativa.

3 Conforme a ABNT, resumos devem ser elaborados com corpo 12 e entrelinhas 1,5, contudo, para fins deste artigo, configuramos os textos com corpo 11 e entrelinhas simples.

\section{LINHA D'́GUA}




\section{Texto 2 - versão revisada}

Esta dissertação está inserida na linha de pesquisa Leitura, Escrita e Ensino de Língua Portuguesa, do Programa de Estudos Pós-Graduados em Língua Portuguesa, da Pontifícia Universidade Católica de São Paulo, e tem como tema a construção da argumentação em redações do $9^{\circ}$ ano do Ensino Fundamental produzidas no contexto do Sistema de Avaliação de Rendimento Escolar do Estado de São Paulo (Saresp). A pergunta de pesquisa que orienta este estudo é: Como os alunos do $9^{\circ}$ ano do Ensino Fundamental que realizam o Saresp organizam as sequências textuais argumentativas e utilizam os operadores argumentativos na construção de textos dissertativo-argumentativos do gênero artigo de opinião? Para respondermos a esse questionamento, estabelecemos como objetivo geral verificar a construção da argumentação em textos de alunos do $9^{\circ}$ ano do Ensino Fundamental no contexto do Saresp 2014. Já os objetivos específicos são: 1) identificar, descrever e analisar as sequências argumentativas e os operadores argumentativos presentes nos textos analisados e 2) discutir a relação entre as sequências e os operadores argumentativos na constituição da argumentação nesses textos. O aporte teórico que fundamenta esta pesquisa é composto principalmente por Koch (2009), Marcuschi (2008), Cabral (2017), Travaglia (2017) e Adam (1992; 2011). O corpus é composto por trinta textos, selecionados de um conjunto de cem produções. Nesta dissertação, consideramos quatro textos, cujas análises apresentamos a título de exemplificação. Estabelecemos como categorias de análise as sequências textuais argumentativas e os operadores argumentativos. Os resultados obtidos demonstram que, embora os alunos construam textos dissertativos-argumentativos e empreguem os operadores argumentativos, não o fazem visando à efetiva persuasão e convencimento do interlocutor, o que evidencia a necessidade de se desenvolver conteúdos e estratégias de ensino de escrita que privilegiem a argumentação.

Palavras-chave: Texto dissertativo-argumentativo. Sequência textual argumentativa. Operadores argumentativos. Saresp.

Ao compararmos o texto 1 com o texto 2, notamos, primeiramente, uma diferença em relação ao aspecto visual, que reflete a estrutura do texto: resumos acadêmicos, como orienta a ABNT (NBR 6028, 2003), são escritos em um único bloco, sem entrada de parágrafo.

Considerando os elementos destacados em negrito, que se referem àqueles que comumente compõem textos desse gênero, podemos perceber que o texto 1 traz explícitos apenas tema e corpus. A impressão ao ler o texto 1 é de que seu autor o escreveu sem ter o conhecimento acerca de sua estrutura e de seu propósito comunicativo. Já no texto 2, estão elencados os elementos constituintes necessários à compreensão do leitor acerca do que trata a pesquisa: tema, pergunta de pesquisa, objetivos geral e específicos, aporte teórico, corpus, categorias de análise e resultados obtidos. Como ensinam Marquesi, Cabral e Rodrigues (2020, p. 177), o resumo, organizado segundo suas partes canônicas, "cumpre sua finalidade comunicativa de motivar e preparar o leitor para a leitura do texto integral".

Especificamente em relação ao aporte teórico, no texto 1, embora não esteja sinalizado por meio de um termo explícito que o indique, ele se faz presente, mas de forma diluída ao 
longo de três parágrafos, o que prejudica o conteúdo do resumo e não permite ao leitor saber exatamente quais teóricos subsidiam a pesquisa no que se refere a determinado tópico. Entendemos que a imprecisão em relação aos dados pertinentes ao quadro teórico pode fazer com que o leitor não queira avançar na leitura do trabalho.

Outro trecho que não favorece a compreensão do leitor está no segundo parágrafo, ainda no texto 1, "Importante para o ensino de Língua Portuguesa [...] Marcuschi (2008)", em que as ideias estão apenas justapostas. Nele não é possível estabelecer com certeza o que é "importante para o ensino de Língua Portuguesa", aspecto que compromete toda estrutura desse parágrafo.

É importante destacar também os elementos relacionados à normatização de referências, que foram ajustados na versão revisada, por exemplo, "Adam (1992, 2011)", no texto 1, passou a "Adam (1992; 2011)", no texto 2; as palavras-chave devem ser no mínimo três, que melhor representem o conteúdo do trabalho, separadas por ponto final, e apenas a primeira letra deve ser maiúscula (ABNT, NBR 6028, 2003).

Notamos que algumas das inadequações relativas à norma culta presentes no texto 1 , como, por exemplo, "tomamos as estratégias da argumentação discursiva que permite lançar mão de uma tese (grifo nosso)", em que não foi observada a concordância, acabaram sendo eliminadas no texto revisado.

A versão reescrita do texto 1 resultante da metodologia aplicada no trabalho de revisão textual evidencia que o conhecimento acerca da estrutura composicional e do propósito comunicativo do gênero resumo acadêmico, assim como o conhecimento acerca das categorias orientadoras da revisão textual constituem subsídios relevantes para que os alunos aprimorem não apenas os textos dos colegas, mas também os próprios textos. Em sentido mais amplo, Pinto (2016) reconhece que o saber escrever textos acadêmicos, conforme dita a comunidade científica de uma dada área, é um passo fundamental para integrar essa comunidade. Assim, escrever no contexto da pós-graduação não se trata apenas de produzir textos, trata-se também de praticar o exercício de se fazer aceito por esse meio.

\section{Considerações finais}

Pensarmos o ensino da escrita como processo, do qual fazem parte as etapas de reescrita e revisão, da perspectiva das metodologias ativas de aprendizagem, abre-nos horizontes para o trabalho com o texto, especialmente no âmbito da pós-graduação, em que os alunos são solicitados a produzirem textos de gêneros muito específicos, que satisfaçam propósitos comunicativos claramente estabelecidos.

Ao considerarmos a aprendizagem por pares adaptada ao contexto da revisão textual, exemplificando por meio de uma aplicação, objetivamos evidenciar não só a importância das etapas que compõem a atividade de escrita, que, como ressalta Pinto (2017), está longe de ser linear, mas também demonstrar que o aluno pode assumir o papel ativo na própria

\section{LINHA DÁGUA}


aprendizagem, especificamente, em relação a como proceder à revisão e também à reescrita de seus próprios textos.

Essa abordagem permite-nos considerar possibilidades para o ensino e para a aprendizagem da escrita de textos acadêmicos alinhadas a metodologias que privilegiem o protagonismo do estudante e o papel de orientação e mediação do professor, em atividades em que prevaleçam a interatividade e a colaboração na construção do conhecimento.

\section{Referências}

AGUIAR, A. P. S.; MARQUESI, S. C. Escrita, revisão e reescrita de textos acadêmicos: o encadeamento entre parágrafos. Verbum - Cadernos de Pós-Graduação, v. 8, n. 2, p. 90-109, 2019. Disponível em: https://revistas.pucsp.br/index.php/verbum/article/view/44920/pdf. Acesso em: 30 nov. 2020.

ALBUQUERQUE, A. G.; SAMPAIO, Y. S. S. A maiêutica socrática como precursora das metodologias ativas: uma análise sobre a construção do senso crítico no ensino jurídico brasileiro. In: QUINTILHANO, S. R.; TONDATO, R. (org.). Metodologias ativas no ensino superior - práticas pedagógicas. Jundiaí: Paco Editorial, 2019.

ARAUJO, I. S.; MAZUR, E. Instrução pelos colegas e Ensino sob medida: uma proposta para o engajamento dos alunos no processo de ensino-aprendizagem de Física. Caderno Brasileiro de Ensino de Física, Florianópolis, v. 30, n. 2, p. 362-384, ago. 2013. Disponível em: https://periodicos.ufsc.br/index.php/fisica/article/view/2175-7941.2013v30n2p362. DOI: http://dx.doi.org/10.5007/2175-7941.2013v30n2p362. Acesso em: 27 dez. 2020.

ASSOCIAÇÃO BRASILEIRA DE NORMAS TÉCNICAS. NBR 6028. Informação e documentação: resumo: apresentação. Rio de Janeiro, 2003.

BACICH, L.; MORAN, J. Metodologias ativas para uma educação inovadora - uma abordagem teórico-prática. Porto Alegre: Penso, 2017.

BAZERMAN, Charles. Retórica da ação letrada. Trad. Adail Sobral et al. São Paulo: Parábola Editorial, 2015.

BAKHTIN, M. (V. N. Volochínov). Marxismo e filosofia da linguagem. Trad. Michel Lahud e Yara Frateschi Vieira. 13. ed. São Paulo: Hucitec, 2009 [1929].

BARTON, D.; LEE, C. Linguagem online - Textos e práticas digitais. Trad. Milton C. Mota. São Paulo: Parábola, 2015.

BELOTI, A.; MENEGASSI, R. J. A compreensão da escrita como processo na formação docente do PIBID. Raído, v. 12, n. 27, p. 247-263, jan.-jun. 2017. Disponível em: https://bit.ly/3qhTA0C. DOI: 10.30612/raido.v11i27.5665. Acesso em: 30 nov. 2020.

BERGMANN, J.; SAMS, A. Sala de aula invertida - Uma metodologia ativa de aprendizagem. Trad. Afonso Celso da Cunha Serra. Rio de Janeiro: LTC, 2016.

CHAQUIME, L. P.; MILL, D. Metodologias ativas (verbete). In: MILL, D. (org.). Dicionário crítico de educação e tecnologias e de educação a distância. Campinas: Papirus, 2018.

Charaudeau, P.; MAIngueneaU, D. Dicionário de Análise do Discurso. Coord. da tradução Fabiana Komesu. São Paulo: Contexto, 2008. 
FALLAHI, C. R. Improving college student's writing skills. In: GRIGORENKO, E. L.; MAMBRINO, E.; PREISS, D. D. Writing - a mosaic f new perspectives. New York: Psychology Press, 2012.

FÁVERO, L. L. et al. Interação em diferentes contextos. In: BENTES, A. C.; LEITE, M. Q.(org.). Linguística de texto e análise da conversação. São Paulo: Cortez, 2010.

FIAD, R. S., MAYRINK-SABINSON, M. L. T. A escrita como trabalho. In: MARTINS, M. H. (org.) Questões de linguagem. São Paulo: Contexto, 1991.

FILATRO, A.; CAVALCANTI, C. C. Metodologias inov-ativas na educação presencial, a distância e corporativa. São Paulo: Saraiva. 2018.

FREIRE, P. Pedagogia do oprimido. Rio de Janeiro: Paz e Terra, 2019.

KOCH, I. V. Introdução à Lingüística textual - trajetória e grandes temas. São Paulo: Martins Fontes, 2006.

KOCH, I. V. Inter-ação pela linguagem. São Paulo: Contesto, 2007.

LEITE, M. Q. Resumo. São Paulo: Paulistana, 2006.

LOPES, R. M. SILVA FILHO, M. V.; MARSDEN, M.; ALVES, N. G. Aprendizagem baseada em problemas: uma experiência no ensino de química toxicológica. Quim. Nova, v. 34, n. 7, p. 1275-1280, 2011. Disponível em: https://bit.ly/3oelmJU. DOI: http://dx.doi.org/10.1590/S0100-40422011000700029. Acesso em: 10 nov. 2020.

MARQUESI, S. C.; CABRAL, A. L. T.; RODRIGUES, M. das G. Escrita acadêmica: argumentação e efeitos de sentido. In: OLIVEIRA, Esther Gomes et al. Discurso $e$ argumentação: tecendo os efeitos de sentido. Campinas: Pontes, 2020.

MARQUESI, S. C.; SILVEIRA, I. F. Tecnologias da Informação e Comunicação como suporte à aprendizagem ativa de língua portuguesa no ensino superior. Linha D'Água, v. 28, n. 1, p. 137-154, 2015.2 Disponível em: http://www.revistas.usp.br/linhadagua/article/view/97451/98230. DOI: http://dx.doi.org/10.11606/issn.2236-4242.v28i1p137-154. Acesso em: 18 dez. 2020.

MATTAR, J. Metodologias ativas para a educação presencial, blended e a distância. São Paulo: Artesanato Educacional, 2017.

MORIN, E. Introdução ao pensamento complexo. 4. ed. Trad. Eliane Lisboa. Porto Alegre: Sulina, 2011.

MORAN, J. Metodologias ativas para uma aprendizagem mais profunda. In: BACICH, L.; MORAN, J. (org.). Metodologias ativas para uma educação inovadora - uma abordagem teórico-prática. Porto Alegre: Penso, 2018. E-Book.

MOTTA-ROTH, D.; HENDGES, G. R. Produção textual na Universidade. São Paulo: Parábola, 2010.

PINTO, M. da G. L. C. A leitura/escrita na Universidade e para lá dos seus muros. In: MARÇALO, M. J. et al. Língua portuguesa: ultrapassar fronteiras, juntar culturas, Universidade de Évora, 2010. Disponível em: https://repositorioaberto.up.pt/bitstream/10216/39388/2/gracapintoleitura000113074.pdf. Acesso em: 20 nov. 2020. 
PINTO, M. da G. L. C. A escrita: um processo recursivo movido pela revisão? In: PINTO, M. da G. L. C. A escrita: o papel da universidade na sua otimização. Porto: Faculdade de Letras da Universidade do Porto, 2014.

PINTO, M. da G. L. C. A escrita académica: um jogo de forças entre a geração de ideias e a sua concretização. Signo, v. 41, p. 53-71, 2016. Disponível em: $<$ https://online.unisc.br/seer/index.php/signo/article/view/7325/pdf $>$. $\quad$ DOI: 10.17058/signo.v1i1.7325. Acesso em: 10 dez. 2020

PINTO, M. da G. L. C. A Da "manta de retalhos" ao "tapete de Arraiolos": transformação de tecedura também aplicável à escrita académica. Atas do V SIMELP - Simpósio Mundial de Estudos de Língua Portuguesa, p. 4353-4375, 2017. Disponível em: http://sibaese.unisalento.it/index.php/dvaf/article./view/18143/15484. Acesso em: 10 dez. 2020.

PINTO, M. da G. L. C. A escrita: uma prática movida pela busca da melhor adequação da execução à intenção. Revista Observatório, v. 4, n. 4, 2018. Disponível em: https://sistemas.uft.edu.br/periodicos/index.php/observatorio/article/view/5564/13325. DOI: 10.20873/uft.2447-4266.2018v4n4p763 Acesso em: 20 dez. 2020.

SOBRAL, A. Do dialogismo ao gênero - as bases do pensamento do Círculo de Bakhtin. Campinas: Mercado das Letras, 2009.

SOUZA, P. H. de. Metodologias ativas: o que as escolas podem aprender. Belo Horizonte: Conhecimento Editora, 2020. E-book.

VAN DIJK, T. Cognição, discurso e interação. São Paulo: Contexto, 1992.

VALENTE, J. A.; ALMEIDA, M. E. B.; GERALDINI, A. F. S. Metodologias ativas: das concepções às práticas em distintos níveis de ensino. Rev. Diálogo Educ., Curitiba, v. 17, n. 52, p. 455-478, abr.jun. $2017 . \quad$ Disponível em: https://periodicos.pucpr.br/index.php/dialogoeducacional/article/view/9900. DOI: http://dx.doi.org/10.7213/1981-416X.17.052.DS07 Acesso em: 10 out. 2020.

VYGOTSKY, L. S. Pensamento e linguagem. Trad. Jéferson Luiz Camargo. São Paulo: Martins Fontes, 2008.

Recebido: 10/01/2021.

Aprovado: 11/02/2021. 